\title{
The Use of Life Cycle Assessment in the Support of the Development of Fungal Food Products from Surplus Bread
}

\author{
Pedro Brancoli *(D), Rebecca Gmoser (D), Mohammad J. Taherzadeh (D) and Kim Bolton \\ Swedish Centre for Resource Recovery, University of Borås, 50190 Borås, Sweden; rebecca.gmoser@hb.se (R.G.); \\ mohammad.taherzadeh@hb.se (M.J.T.); kim.bolton@hb.se (K.B.) \\ * Correspondence: pedro.brancoli@hb.se
}

check for

updates

Citation: Brancoli, P.; Gmoser, R.; Taherzadeh, M.J.; Bolton, K. The Use of Life Cycle Assessment in the Support of the Development of Fungal Food Products from Surplus Bread. Fermentation 2021, 7, 173. https://doi.org/10.3390/ fermentation7030173

Academic Editors: Alessia Tropea and Giuseppa Di Bella

Received: 19 July 2021

Accepted: 27 August 2021

Published: 30 August 2021

Publisher's Note: MDPI stays neutral with regard to jurisdictional claims in published maps and institutional affiliations.

Copyright: (c) 2021 by the authors. Licensee MDPI, Basel, Switzerland. This article is an open access article distributed under the terms and conditions of the Creative Commons Attribution (CC BY) license (https:/ / creativecommons.org/licenses/by/ $4.0 /)$.

\begin{abstract}
The use of food waste as feedstock in the manufacture of high-value products is a promising avenue to contribute to circular economy. Considering that the majority of environmental impacts of products are determined in the early phases of product development, it is crucial to integrate life cycle assessment during these phases. This study integrates environmental considerations in the development of solid-state fermentation based on the cultivation of $N$. intermedia for the production of a fungal food product using surplus bread as a substrate. The product can be sold as a readyto-eat meal to reduce waste while generating additional income. Four inoculation scenarios were proposed, based on the use of bread, molasses, and glucose as substrate, and one scenario based on backslopping. The environmental performance was assessed, and the quality of the fungal product was evaluated in terms of morphology and protein content. The protein content of the fungal food product was similar in all scenarios, varying from $25 \%$ to $29 \%$. The scenario based on backslopping showed the lowest environmental impacts while maintaining high protein content. The results show that the inoculum production and the solid-state fermentation are the two environmental hotspots and should be in focus when optimizing the process.
\end{abstract}

Keywords: life cycle assessment; Neurospora intermedia; bread; process development

\section{Introduction}

In food production, extensive resources such as water, land, energy and nutrients are used with significant impact to the environment. It is forecasted that by 2050, the demand for agricultural products will increase by $35-50 \%$ due to a growing population and rising incomes, leading to higher pressure on the environment [1]. The problem is aggravated by the significant wastage of food throughout the supply chain. The wastage of food represents not only the loss of the product itself, but also all the resources used in food production, transportation and packaging.

The provision of animal-based protein generally has a higher environmental impact compared with vegetable or fungi-based proteins [2]. Concerns regarding the ethical and environmental implications of meat consumption have increased the demand for meat substitutes, such as those based on legumes and fungi [3]. Recently, the use of filamentous fungi as a commercial food product has gained considerable attention, due to its high protein content, the presence of essential amino acids and easy digestibility [4,5]. Filamentous fungi have traditionally been used by different societies as food, e.g., tempeh and oncom are indigenous staple foods in Indonesia [6,7]. One example of a product currently sold in the European market is Quorn ${ }^{\mathrm{TM}}$, which is made from the filamentous fungus Fusarium venenatum cultivated in synthetic medium with glucose, ammonium and mixed with egg albumen [8]. One problem with this product is the high cost of the cultivation medium [4]. Moreover, Smetana et al. [9] performed an environmental assessment of a similar product based on mycoprotein cultivated in molasses and concluded that the substrate is an environmental hotspot in the system. Therefore, it is relevant to consider other types of substrates to decrease production costs and environmental impacts. 
One alternative substrate for fungal cultivation is surplus bread. The valorisation of food surplus into high-value products has gained interest as part of the strategies of transition to a bio-based economy grounded on a sustainable use of resources. Bread is rich in carbohydrates and its porosity makes it an ideal substrate for fungal cultivation $[6,10]$. Moreover, bread is a product with high waste generation, particularly at the level of the consumer and at the supplier-retailer interface. In the UK, it was estimated that $10 \%$ of all food waste are bakery products [11]. Brancoli et al. [12] studied food waste from retailers in Sweden and concluded that bread is a product category with large environmental impacts and economic costs [12]. In Sweden, the quantity of bread waste generated was estimated to be 80,410 tons/year, of which 28,200 tons/year are generated at the retail level [13]. The large waste volumes of uniform composition and quality, and the distribution model in which bread is sold makes it a good substrate for manufacturers who strive for stable delivery of raw materials.

There are mainly two different categories of bread, bake-off and pre-packaged. The technology proposed in this article can be used for both categories. Bake-off are products baked from pre-made dough in supermarkets or by a bakery. Pre-packaged bread is produced by the bakeries, and in some countries, it is often sold to retailers under takeback agreements (TBAs) [13-15]. In such agreements, the bakeries collect the bread that is not sold in the supermarkets, and here, bread waste is segregated from other food waste fractions from the retailers. This enables alternative pathways for the waste management and valorisation of the unsold bread. These pathways should preferably be located at higher levels in the food waste hierarchy, such as the production of fungal biomass for food, ethanol or animal feed $[16,17]$. Nevertheless, it is necessary to ensure that such technologies are sustainable and that they minimize the use of natural resources and the generation of waste as well as emissions of pollutants over their life cycles.

The life cycle assessment (LCA) methodology can be used to assess the environmental performance of a product to ensure its sustainability. The methodology can also be applied to support the early design stages in the development of the product by assessing the implication of design choices on the environmental performance of the technology [18]. Such studies are crucial since they can identify and prevent environmental impacts before the technology has been embedded by path dependency and lock-in [19]. Decisions made in the early stages of product development can have a significant influence on its subsequent environmental impacts. McAloone and Bey [20] estimated that $80 \%$ of the environmental performance of a product is determined by decisions made in the early stages of the technology development. For this reason, the European Union [21] recommends the use of LCA in product development to guarantee its sustainability.

Research on life cycle assessment of valorisation of bread waste is primarily focused on the lower stages of the food waste hierarchy. Few studies address bread waste valorisation into high-value products. Moreover, most of the research focuses on technologies with high technology readiness levels. Previous studies have investigated the environmental performance of bread waste management and valorisation alternatives, such as anaerobic digestion and incineration [22], conversion into biofuels [17], animal feed [17,23], and value-added chemicals [24]. There is a large body of research on the development of new technologies to valorise bread to high value products $[6,25,26]$, but most of this research does not integrate lifecycle thinking into the early stages of the process development, increasing the risk for sub optimization of the technology.

The aim of this study was to integrate environmental considerations in the early stages of the development of a solid-state fermentation (SSF) process using bread as feedstock for the production of a protein-rich food product. The SSF process is proposed to be implemented as a stand-alone business, or on-site in small-scale bakeries to recover their otherwise discarded surplus bread. The technology can also be implemented in supermarkets that have a fresh bakery department in house, i.e., supermarkets that bake their own bread. The food product can be sold as a ready-to-eat meal directly to customers 
to reduce waste while generating additional income from the fungal product and provide a new sustainable food alternative that can replace other less sustainable options.

The goal of this study is to support the technology developers during the design and development phases by assessing the environmental sustainability of a range of possible scenarios in which the technology can operate. This will enable a better understanding of the relation between design choices and the environmental performance of the technology, as well as allow the steering of the technology towards solutions with a lower environmental impact. Moreover, research on fungal growth patterns in solid-state cultures are limited and this study investigates whether morphological differences of the inoculation culture influence the performance in the subsequent SSF step.

\section{Materials and Methods}

The process development was iterative and used the concept of proxy technology transfer-process [27], which considers that emerging technologies are not often based on completely new processes. Instead, it relies on a new application of existing technologies. The development of the process started with the assessment of an incumbent technology, namely the production of mycoprotein cultivated in molasses to identify hotspots in the system. The first results were then communicated to the researchers involved in the process development, starting an iterative approach wherein the hotspots in the system are identified and alternatives were proposed and assessed. In total, four different scenarios for the inoculation were proposed and compared in relation to the environmental performance and characteristics of the final product, such as protein content and morphology. A detailed description of the scenarios is available in Section 2.1.

\subsection{Process Description}

The basic steps in the process are the drying and grinding of the bread, mixing with water and the starter spores (inoculum), and fermentation. The later processes after fermentation, such as frying, and freezing for later consumption are excluded in the study (Figure 1).

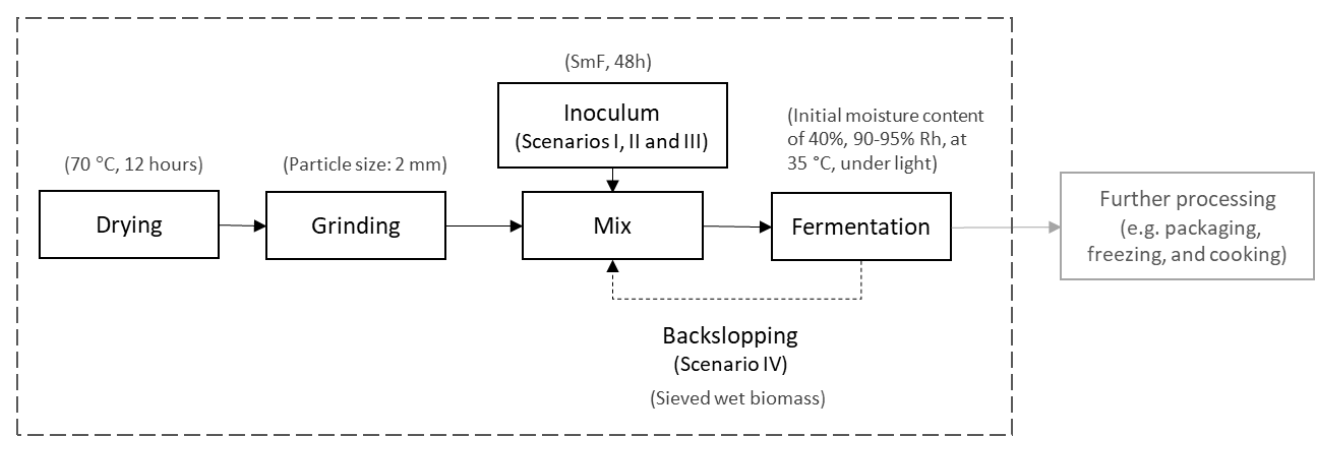

Figure 1. Basic process flow chart. The conditions of each process are described in brackets. The dotted box represents the system boundaries of the study. The further processing of the fungal biomass after fermentation is not included in the system boundaries.

\subsubsection{Substrate and Fungus}

Steinbrenner \& Nyberg (Mölndal, Sweden) kindly provided unsold fresh sourdough bread that showed no signs of mould contamination. The bread was prepared according to the process described in Gmoser et al [25]. Samples were autoclaved and stored in airtight containers at room temperature prior to use. The edible food grade filamentous fungus Neurospora intermedia CBS 131.92 (Centraalbureau voor Schimmelcultures, Utrecht, The Netherlands) was used. The fungus was maintained on potato dextrose agar (PDA) plates containing $20 \mathrm{~g} / \mathrm{L}$ glucose $20,15 \mathrm{~g} / \mathrm{L}$ agar and $4 \mathrm{~g} / \mathrm{L}$ potato extract. The PDA plates were prepared by incubation for 5 days at $30{ }^{\circ} \mathrm{C}$ followed by storage at $4{ }^{\circ} \mathrm{C}$. The spore solution was prepared by flooding each plate with $20 \mathrm{~mL}$ of distilled water, using a 
disposable plastic spreader to gently release the spores and transferring them to a sterile slant tube. The spore solution $\left(2.5 \times 10^{6}\right.$ spores $\left./ \mathrm{mL}\right)$ was used to prepare the four different inoculations (one for each of the scenarios). A detailed description of the conditions of fermentation is given in Section 2.1.3.

\subsubsection{Design of the Inoculation}

The choice of the nutrient source was based on existing technologies. The inoculum for Scenario I is produced in a similar way to the inoculum production for tempeh as described in Wiloso et al. [28], but instead of using white rice or other grains, it is based on stale bread. Production of the inoculum for Scenario II, which is based on a similar process to cultivate yeast [29], used a synthetic medium based on molasses and ammonium chloride. Scenario III is based on glucose, and it was adapted from Jungbluth et al. [30], which describes the production of mycoprotein for Quorn ${ }^{\mathrm{TM}}$ (Table 1).

Table 1. Inventory analysis for the different scenarios for the production of the fermented fungal product per functional unit. The indented substances in italic refer to the inputs related to the production of the fungal biomass (inoculum) used for the inoculation.

\begin{tabular}{cccccc}
\hline & Unit & Scenario I & Scenario II & Scenario. III & Scenario IV \\
\hline Inputs & & & & & \\
Bread & $\mathrm{kg}$ & 2.0 & 2.0 & 2.0 & 2.0 \\
Inoculum & $\mathrm{g}$ & 10 & 10 & 10 & $29 *$ \\
Water & $\mathrm{l}$ & 2.63 & 1.81 & 1.92 & - \\
Glucose & $\mathrm{g}$ & - & - & 38.50 & - \\
$\mathrm{NH}_{4} \mathrm{Cl}$ & $\mathrm{g}$ & - & 16.28 & 14.50 & - \\
$\mathrm{NaOH}$ & $\mathrm{g}$ & - & - & 0.62 & - \\
Molasses & $\mathrm{g}$ & - & 0.36 & - & - \\
Bread & $\mathrm{g}$ & 52.60 & - & - & - \\
Electricity & $\mathrm{kWh}$ & 0.065 & 0.033 & 0.033 & 0.033 \\
Water for mixing & $\mathrm{l}$ & 1.34 & 1.34 & 1.34 & 1.34 \\
Electricity for drying & $\mathrm{kWh}$ & 0.53 & 0.53 & 0.53 & 0.53 \\
Electricity for grinding & $\mathrm{kWh}$ & 0.024 & 0.024 & 0.024 & 0.024 \\
Electricity for SSF & $\mathrm{kWh}$ & 1.55 & 1.55 & 1.55 & 1.55 \\
Outputs & & & & & \\
Fermented fungal product * & $\mathrm{kg}$ & 1 & 1 & 1 & 1
\end{tabular}

* Calculation based on the mass balance revealed by Wang et al. [31] and the starch, protein and moisture content in the samples.

The three submerged fermentation $(\mathrm{SmF})$ processes (Scenarios I, II and III) were inoculated with $10 \mathrm{~mL} / \mathrm{L}$ of the spore solution, cultivated aerobically for $48 \mathrm{~h}$ in cotton plugged $250 \mathrm{~mL}$ Erlenmeyer flasks containing $100 \mathrm{~mL}$ of medium autoclaved at $121{ }^{\circ} \mathrm{C}$ for $20 \mathrm{~min}$. The initial $\mathrm{pH}$ of the medium was adjusted to 5.5 with $2 \mathrm{M} \mathrm{HCl}$ or $\mathrm{NaOH}$. The different medium compositions are summarized in Table 1. A water bath (Grant OLS-Aqua pro, Cambridge, UK) was used to maintain the temperature with orbital shaking at $125 \mathrm{rpm}$ (radius of $9 \mathrm{~mm}$ ) for $48 \mathrm{~h}$. At the end of the fermentation, the wet biomass from each shake flask was harvested by pouring the cultivation medium through a $1 \mathrm{~mm}^{2}$ pore area fine mesh and washed with distilled water. The liquid fraction was collected separately and frozen for further analysis. The moisture content of the fungal biomass was measured gravimetrically and sieved wet biomass was used directly as inoculum for the solid-state fermentation step.

Scenario IV relies on the recirculation (backslopping) of part of the fermented product from a previous batch as the inoculum. The solid-state fermentation (SSF) on stale bread used as inoculum was prepared according to the SSF process below, except that $0.5 \mathrm{~mL}$ of spore solution was used as inoculum instead. Based on an assumption that the fungal fermented final product contained 35\% fungal biomass, with a moisture content of $60 \%$, in the substrate-fungal matrix after 5 days of solid-state fermentation [25], the amount needed for backslopping was set to $0.01 \%$ dry weight of the substrate. 


\subsubsection{Solid State Fermentation}

Cultivation of $N$. intermedia was conducted in sterile petri dishes $(100 \mathrm{~mm} \times 20 \mathrm{~mm})$. A total dry weight of $15 \mathrm{~g}$ breadcrumbs was inoculated with $N$. intermedia separately for each petri dish. The initial moisture content was adjusted to $40 \%$ (on a dry basis ( $w / w$, $\mathrm{db}$ ) with distilled water, after which each sample was mixed evenly, and a lid was placed on the petri dish. Solid-state fermentation was conducted batch wise for 2-10 days in a climatic test cabinet (NUVE test cabinet TK 120, Ankara, Turkey) at $90 \%-95 \%$ relative humidity (Rh) $\pm 1 \%$, at $35^{\circ} \mathrm{C}$ under light. The light source was applied to increase pigment production in the fungal biomass in order to form a visually appealing product with improved nutritional value $[6,25]$. The petri dishes were flipped every second day. At the end of fermentation, samples were dried at $45^{\circ} \mathrm{C}$. Effects of days of fermentation on the final weight and protein content in the fungal-bread product were investigated as well as a visual observation on morphology after the SmF step.

\subsection{Analyses}

The fungal spore concentration was determined using a Bürker counting chamber. The final moisture content, the amount of fungal biomass harvested after SmF, and fungalbread product used as inoculum in Sc. IV were determined gravimetrically. Preparation of samples and measurement of the protein content by Kjeldahl digestion using a 2020 Kjeltec Digestor and a 2400 Kjeltec Analyser unit (FOSS Analytical A/S, Hilleröd, Denmark) was performed following the same procedure as in Gmoser et al. [25]. Total starch analysis was accomplished by $\alpha$-amlylase/amylogluco-sidase/hexokinase method following the procedure provided in the Total Starch HK Assay Kit (Megazyme International Ltd., Bray, Ireland).

\subsection{Statistical Analysis}

Experiments on the SSF were performed in duplicate $(n=2)$ and two analytical replicates were performed on each batch $(a=2)$. Values present the mean value of the measurement $\pm \mathrm{SD}$. Raw data were statistically analysed using the software package MINITAB $^{\circledR \circledast}$ (version 17.1.0, Minitab Inc., State College, PA, USA). Analysis of variance (ANOVA) was determined using general linear model with a 95\% confidence level followed by Tukey's multiple comparison test. A linear factorial regression model of the data was also conducted with the four inoculation methods as factor levels and days of SSF ( $2-8$ days) as continuous control with protein concentration as output.

\subsection{Life Cycle Assessment}

The functional unit for the environmental assessment is $1 \mathrm{~kg}$ of fermented fungal product after the fermentation step. The selection of a mass unit was connected with the ability to compare results with those available in the literature. The system boundaries are cradle-to-gate as described in Section 2.1. The geographical scope is Sweden. The characterization method ReCiPe (ReCiPe 2016 v1.1 midpoint and endpoint methods, Hierarchist version) [32], was used due to its broad set of midpoint impact categories and the possibility of using both midpoint and endpoint methods [32].

The inventory was built using primary data flows from the laboratory experiments, which were initially based on data from the literature $[28-30,33,34]$ and further developed based on the results from the trial experiments. The energy consumption of the equipment was estimated based on the methodology described in Piccinno et al. [35] for scaling up laboratory data. Capital goods are not included in the inventory, as all scenarios are expected to use similar equipment. The ecoinvent database version 3.6 was used for the background processes. Inventory data for the scenarios is available in Table 1. 


\section{Results}

This section describes the experimental results of the solid-state fermentation, in relation to the increase of the protein content over time and the morphology of the inoculum. Moreover, the result for the life cycle assessment is presented.

\subsection{Experimental Results}

There is a significant difference in protein content of the final fungal product after SSF for the different inoculation methods ( $p$ value 0.00 ). The inoculation scenario using molasses (Sc. II) resulted in a higher protein content after SSF compared to glucose (Sc. III), with no significant difference between Scenarios I and IV. The inoculum scenario based on glucose medium (Sc. III) also resulted in a longer lag phase and slower initial exponential growth, possibly due to change in substrate during SSF, while N. intermedia grown on bread (Sc. I) and molasses (Sc. III) was in a more active phase, adapted to bread as substrate and hypothetically, already producing enzymes for complex carbohydrate assimilation, when applied to the SSF step. However, considering the natural variation in biological systems, the relatively small differences between the inoculation methods do not contribute with sufficient support for choosing one scenario over the other.

As expected, the protein content increased over time for all four groups, with a significant increase over every second day ( $p$ value $=0.00$ ) (Figure 2$)$. The highest increase in protein content happened between day four and six for all inoculation methods based on SmF, varying between $38 \%, 49 \%$ and $51 \%$, for Scenarios I, II and III respectively. Inoculum based on backslopping resulted in a slightly higher increase in protein content between day two and four (39\% increase) compared to the other days. The linear regression equations of the four inoculation methods revealed that SmF based on molasses gave the highest average protein increase per day of 4.0, compared to $\mathrm{SmF}$ based on bread, backslopping and $\mathrm{SmF}$ based on glucose of $3.6 \%, 3.4 \%$ and $3.2 \%$ increase per day respectively (consider a $6.6 \%$ lack of fit of the model). By comparing the linear regression equations, it can be seen that the daily increase based on glucose medium is only slightly offset in x-axis (timescale), whereas the protein value reaches approximately the same amount as the other inoculation methods after 8 days SSF.

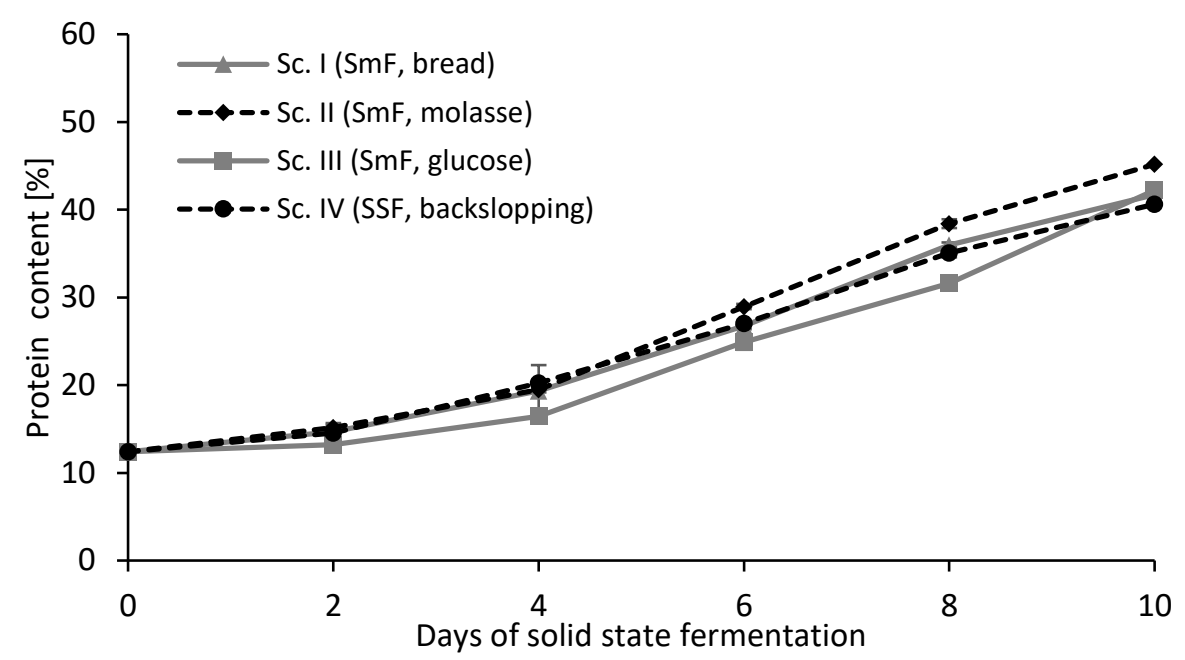

Figure 2. Solid-state cultivation on stale sourdough bread using N. intermedia after 0-10 days cultivation under light at $35^{\circ} \mathrm{C}, 90 \% \mathrm{Rh}$, and $40 \%$ initial moisture content using different inoculation methods: backslopping (black circle, dotted line), submerged fermentation with synthetic medium based on glucose (grey square, solid line), submerged fermentation based on molasses (black diamonds, dotted line) and submerged fermentation based on breadcrumbs (grey triangles, solid line). Results are expressed as the mean value $\pm 95 \%$ confidence level. 
The fungal morphology in the SmF based on molasses medium (Sc. II) resulted in fine, dense pellets, whereas the other SmF cultures resulted in loose filamentous mycelium. SSF based on inoculum from molasses medium gave the highest mean percentage of protein.

\subsection{Life Cycle Assessment}

The relative results for five selected impact assessment categories for the scenarios and separately for the inoculum production process are presented in Figures 3 and 4, respectively. The impact categories described in Figures 3 and 4 are global warming, terrestrial acidification, freshwater eutrophication, marine ecotoxicity and fossil resource scarcity. The results for the remaining thirteen impact categories available in the ReCiPe characterization method [32] is available in Table 2.

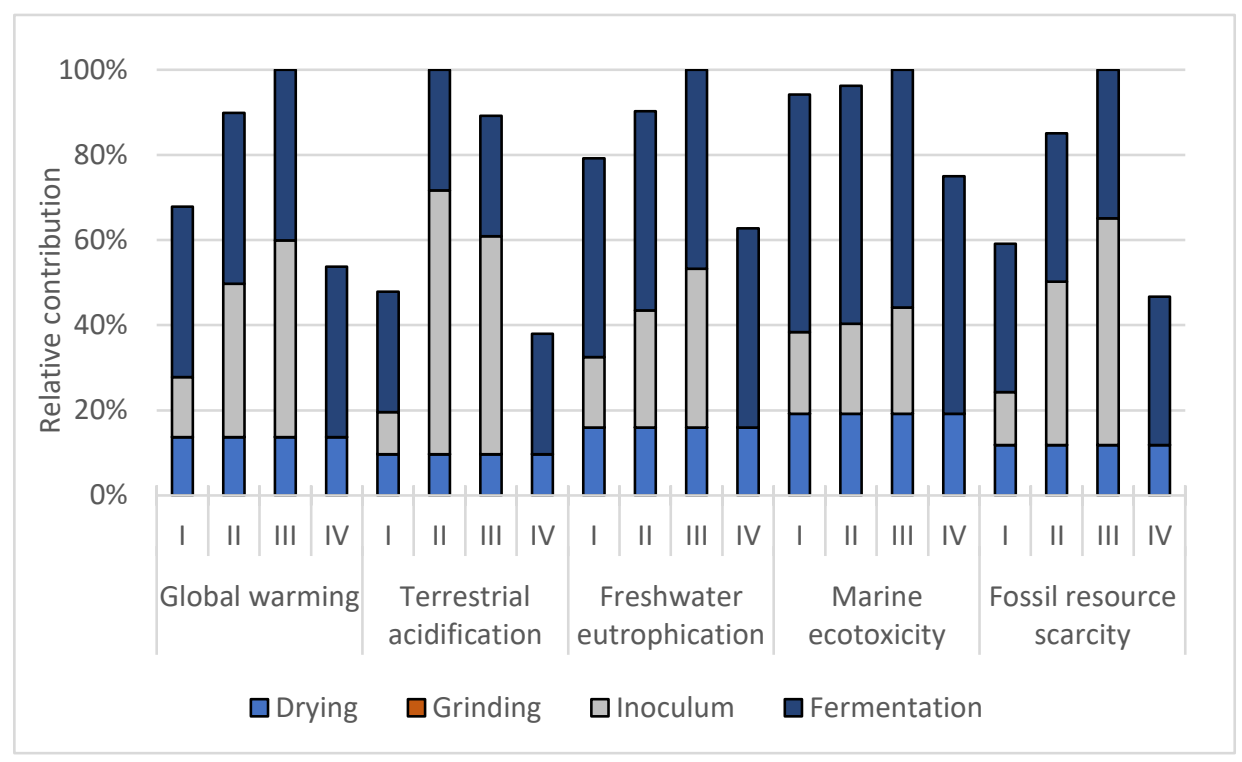

Figure 3. Selected LCIA results for the scenarios for the fermented fungal product production. Sc. I uses bread as the carbon source. Sc. II uses molasses. Sc. III is based on glucose and Sc. IV relies on backslopping, as described in Table 1.

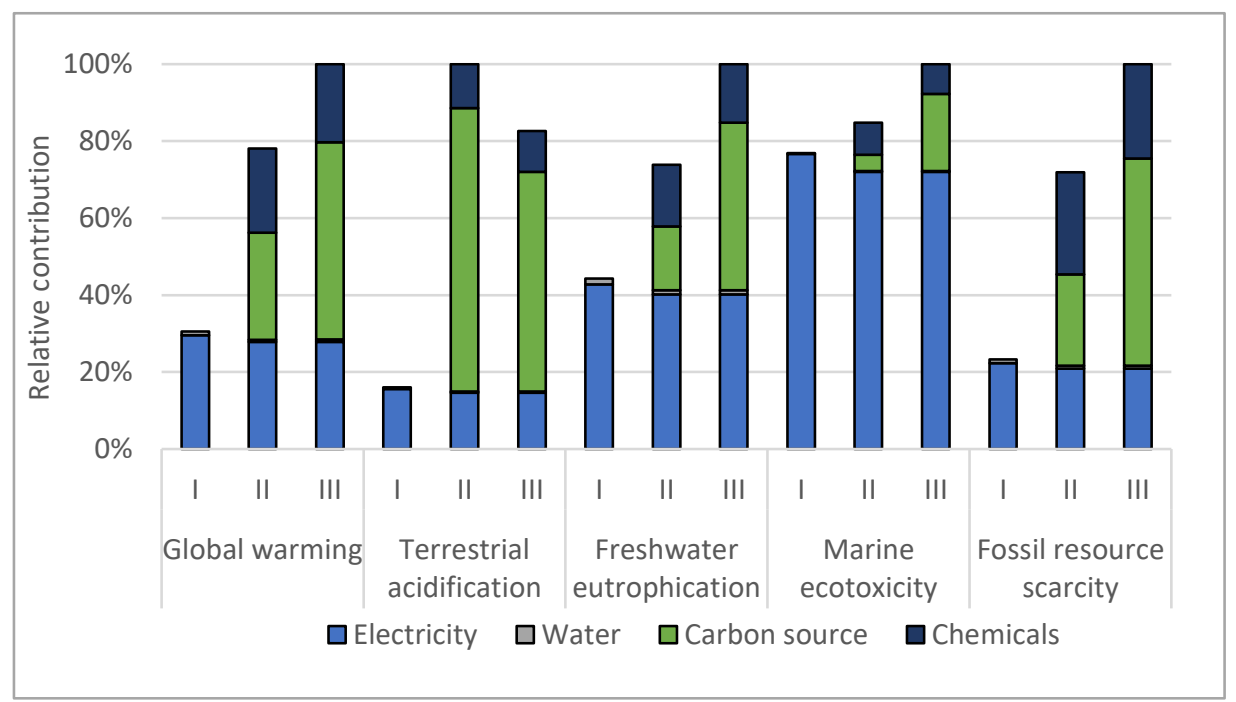

Figure 4. Selected LCIA results for the different inoculation production processes. Sc. I uses breadcrumbs as the carbon source. Sc. II uses molasses. Sc. III is based on glucose. 
Table 2. Impact assessment results for Scenarios I, II, III and IV based on the ReCiPe midpoint impact categories.

\begin{tabular}{|c|c|c|c|c|c|}
\hline Impact Category & Unit & Sc. I & Sc. II & Sc. III & Sc. IV \\
\hline Global warming & $\mathrm{kg} \mathrm{CO} 2 \mathrm{eq}$ & $1.4 \times 10^{-1}$ & $1.9 \times 10^{-1}$ & $2.1 \times 10^{-1}$ & $1.1 \times 10^{-1}$ \\
\hline Stratospheric ozone depletion & $\mathrm{kg}$ CFC-11 eq & $3.0 \times 10^{-7}$ & $6.2 \times 10^{-7}$ & $5.2 \times 10^{-7}$ & $2.4 \times 10^{-7}$ \\
\hline Ionizing radiation & kBq Co-60 eq & $8.0 \times 10^{-1}$ & $7.9 \times 10^{-1}$ & $7.9 \times 10^{-1}$ & $6.4 \times 10^{-1}$ \\
\hline $\begin{array}{l}\text { Ozone formation, Human } \\
\text { health }\end{array}$ & kg NOx eq & $3.5 \times 10^{-4}$ & $4.8 \times 10^{-4}$ & $5.1 \times 10^{-4}$ & $2.8 \times 10^{-4}$ \\
\hline $\begin{array}{l}\text { Fine particulate matter } \\
\text { formation }\end{array}$ & $\mathrm{kg} \mathrm{PM}_{2.5} \mathrm{eq}$ & $2.3 \times 10^{-4}$ & $3.7 \times 10^{-4}$ & $3.8 \times 10^{-4}$ & $1.9 \times 10^{-4}$ \\
\hline Ozone formation, $\mathrm{TE}$ & kg NOx eq & $3.6 \times 10^{-4}$ & $4.9 \times 10^{-4}$ & $5.2 \times 10^{-4}$ & $2.8 \times 10^{-4}$ \\
\hline Terrestrial acidification & $\mathrm{kg} \mathrm{SO}_{2} \mathrm{eq}$ & $5.8 \times 10^{-4}$ & $1.2 \times 10^{-3}$ & $1.1 \times 10^{-3}$ & $4.6 \times 10^{-4}$ \\
\hline Freshwater eutrophication & $\mathrm{kg} p$ eq & $9.4 \times 10^{-5}$ & $1.1 \times 10^{-4}$ & $1.2 \times 10^{-4}$ & $7.54 \times 10^{-5}$ \\
\hline Marine eutrophication & $\mathrm{kg} n$ eq & $1.8 \times 10^{-5}$ & $1.0 \times 10^{-4}$ & $8.5 \times 10^{-5}$ & $1.5 \times 10^{-5}$ \\
\hline Terrestrial ecotoxicity & $\mathrm{kg} 1,4-\mathrm{DCB}$ & $2.2 \times 10^{0}$ & $2.4 \times 10^{0}$ & $2.7 \times 10^{0}$ & $1.8 \times 10^{0}$ \\
\hline Freshwater ecotoxicity & kg 1,4-DCB & $9.4 \times 10^{-2}$ & $9.6 \times 10^{-2}$ & $9.9 \times 10^{-2}$ & $7.5 \times 10^{-2}$ \\
\hline Marine ecotoxicity & kg 1,4-DCB & $1.1 \times 10^{-1}$ & $1.2 \times 10^{-1}$ & $1.2 \times 10^{-1}$ & $9.1 \times 10^{-2}$ \\
\hline Human carcinogenic toxicity & $\mathrm{kg} 1,4-\mathrm{DCB}$ & $1.9 \times 10^{-2}$ & $2.0 \times 10^{-2}$ & $2.1 \times 10^{-2}$ & $1.5 \times 10^{-2}$ \\
\hline $\begin{array}{l}\text { Human non-carcinogenic } \\
\text { toxicity }\end{array}$ & kg 1,4-DCB & $6.0 \times 10^{-1}$ & $6.4 \times 10^{-1}$ & $6.5 \times 10^{-1}$ & $4.8 \times 10^{-1}$ \\
\hline Land use & $\mathrm{m}^{2}$ a crop eq & $6.1 \times 10^{-2}$ & $9.2 \times 10^{-2}$ & $8.7 \times 10^{-2}$ & $4.8 \times 10^{-2}$ \\
\hline Mineral resource scarcity & $\mathrm{kgCu}$ eq & $2.0 \times 10^{-3}$ & $2.4 \times 10^{-3}$ & $2.5 \times 10^{-3}$ & $1.6 \times 10^{-3}$ \\
\hline Fossil resource scarcity & $\mathrm{kg}$ oil eq & $2.6 \times 10^{-2}$ & $3.8 \times 10^{-2}$ & $4.5 \times 10^{-2}$ & $2.1 \times 10^{-2}$ \\
\hline Water consumption & $\mathrm{m}^{3}$ & $2.1 \times 10^{-2}$ & $2.3 \times 10^{-2}$ & $2.2 \times 10^{-2}$ & $1.5 \times 10^{-2}$ \\
\hline
\end{tabular}

Figure 3 indicates that the fermentation step and the choice of inoculum production has a large influence on the environmental burdens associated with the fermented fungal product.

The production of inoculum had a contribution higher than $40 \%$ in 9 out of 18 impact categories assessed in both Sc. II and Sc. III. More specifically, the carbon source used for the inoculum production for these scenarios is a hotspot, as shown in more detail in Figure 4. In Scenario I the inoculation has a relatively lower contribution, ranging from $20 \%$ to $29 \%$. The reason is that it uses stale bread as the carbon source, which is modelled as waste and therefore burden free.

The results indicate that Scenario IV, which is based on backslopping, has the lowest environmental impacts in all of the eighteen categories assessed, followed by Scenario I. Both scenarios substituted glucose or molasses for stale bread, significantly reducing the environmental impacts on the inoculum production. Scenarios II and III had the worst performance in the categories assessed. Scenario II had the worst performance in five impact categories, while Scenario III had the highest impact in 12 environmental impact categories (Table 2).

The solid-state fermentation is also a hotspot, and it contributes significantly to the majority of the impact categories. These impacts are related to the electricity consumption during the process, as shown in Table 1 . The impact is the same for all scenarios, but it has a different relative contribution as shown in Figure 3. Overall, the fermentation step, drying of bread and the inoculation were identified as hotspots in the production of the fungal product (Figure 3).

Figure 4 shows the detailed impact assessment for the different inoculation methods. Sc. IV has no contribution from the inoculum production since it is obtained from backslopping. This assumes that the contribution of the initial inoculum required to make the first batch of fungi is insignificant.

The results indicate that the carbon source used in the inoculum production is a hotspot in the majority of impacts categories in both Scenario II, which uses molasses and Scenario III, based on glucose (Figure 4). The carbon source is responsible for $36 \%$ and $51 \%$ of the impacts on the global warming impact category for Sc. II and Sc. III, respectively. In terrestrial acidification, the contribution is higher, $74 \%$ and $69 \%$ for Sc. II and Sc. III, respectively. Scenario I, conversely, uses stale bread as the carbon source, which is modelled as waste and is, therefore, burden-free. 
Electricity consumption has a significant contribution for both the inoculum production and the overall process. The geographical scope is Sweden, which has a relatively low impact energy system. Therefore, the results of the study are sensitive to the energy mix used.

\section{Discussion}

The environmental impacts of a product are often determined by the decisions made at the early stages of development. For this reason, the development of the product should integrate environmental considerations to minimize the environmental impacts throughout its life cycle without compromising essential characteristics such as function, cost and quality. The estimation of environmental impact at this early stage is challenging due to the limited amount of information available, for example, the energy consumption in the processes. In contrast, the later stages in the product development provide more quantitative data but fewer opportunities to change the system.

Table 3 summarizes and ranks the main technical and environmental differences between the four scenarios studied here, namely the environmental impacts, protein content, lag phase and morphology. These aspects are critical to support the decision of the more suitable method for fungal biomass production using bread as substrate. The environmental impact ranking in Table 3 is based on the single score from ReCiPe endpoint $(\mathrm{H})$ as available in the SimaPro software version 9.1.

Table 3. Summary of technical and environmental indicators for the scenarios assessed. The protein content refers to SSF after 6 days.

\begin{tabular}{ccccc}
\hline Scenarios & Environmental Impact $(\mathbf{m P t})$ & Protein Content & Lag Phase & Morphology \\
\hline Scenario I & 9.7 & $27 \%$ & Short & Dispersed mycelium \\
Scenario II & 12.5 & $29 \%$ & Short & Pellets \\
Scenario III & 13.0 & $25 \%$ & Long & Dispersed mycelium \\
Scenario IV & 7.6 & $27 \%$ & Short & Dispersed mycelium \\
\hline
\end{tabular}

Filamentous fungi grow in different morphological forms in submerged cultures, including freely suspended filamentous mycelia and pellets depending on the genotype of the strain and culture conditions [36]. The growth mode affects the rheological properties of the cultivation medium, and consequently, the overall process performance and final product yields. Generally, the excessive growth of free filamentous mycelia is connected to practical and technical difficulties, such as lower oxygen diffusion, laborious harvesting, high medium viscosity and a relative lower yield of products [37]. These problems associated with the filamentous morphology can be overcome when the fungi grow in the form of pellets, which also have a higher potential for cell reuse and higher productivity due to the possibility of using high-density cultivations [38]. However, including in the pellet form, critical characteristics such as size and compactness versus fluffiness can influence oxygen and substrate transfer rates. The trend in research works has been towards the production of small fluffy pellets. Among the scenarios assessed, only Scenario II grew in the pellet morphology. The slightly shorter lag phase in Scenario II compared to Scenario III further promote this inoculation method since it promotes a faster initiation of the subsequent SSF step. Nevertheless, the environmental impact of Sc. II is significantly higher in comparison with Sc. I and IV (Table 3).

Scenario IV had the lowest environmental impact, and the protein content was sufficient for the intended use. However, one potential drawback with this method is the higher risk of contamination since it is more problematic to sustain a sterile condition at a larger scale when backslopping part of the final product as inoculum compared to inoculum using pure fungal biomass from SmF. Thus, microbiology analysis of the final product and industrial trials need to be assessed before this method can be applied.

Considering the weighted results at Table 3, Scenario I had an environmental impact that is $28 \%$ higher in comparison with Scenario IV, but the results indicate a lower impact in comparison with Scenarios II and III. Moreover, the main advantage of this 
scenario in comparison to Scenario IV is that it is less sensitive to contamination. Scenario I also yields filamentous mycelia morphology. However, further development of this scenario by changes in cultivation conditions such as $\mathrm{pH}$ and aeration can potentially alter the morphology.

The fermentation time is another important aspect influencing both the protein content and the environmental impacts of the final product. The results showed that the protein content for all scenarios reached similar values after 8 days of SSF. However, based on previous studies [6] on the visual appearance and smell of the final product, the SSF step should not be longer than a maximum of eight days and preferably six days if the protein content is sufficient for the intended purpose as food. A direct comparison of the environmental performance of this fungal product with established food products based on mycoprotein requires special attention due to scale-up issues and technology uncertainties inherent in the majority LCAs of products in an early stage of development [18]. Moreover, it is expected that the technology under assessment will need further development in relation to technical aspects and consumer's acceptance.

Jungbluth et al. [30] reported an electricity consumption of $1.17 \mathrm{kWh}$ and a heat consumption of $13 \mathrm{MJ}$ for the industrial production of $1 \mathrm{~kg}$ of mycoprotein at plant. Smetana et al. [9] reported $6 \mathrm{kWh} / \mathrm{kg}$ of mycoprotein ready to eat. The electricity consumption in this study ranged from 2.61 to $2.64 \mathrm{kWh} /$ functional unit for the different scenarios. Nevertheless, it is important to note that a direct comparison is not possible, due to differences in the system boundaries of each study. The system boundaries in this study and Jungbluth et al. [30] end at the plant gate, while Smetana et al. [9] consider the system boundaries until the consumer's plate. There are also discrepancies in the technology readiness level between this study and Jungbluth et al. [30] in which inventory is based on an operational plant.

A huge advantage is that we now have an LCA model that can be used to get updated environmental impacts when the scenarios are adjusted to improve factors such as protein content, lag time and morphology. This allows for environmental impacts to be assessed throughout the development process.

\section{Conclusions}

The current analysis, which included different production pathways for the valorisation of stale bread into fungal biomass according to the environmental impacts, protein content, lag phase and morphology, indicated the potential use of the fungal biomass as a substitute for traditional food products. The technology proposed uses an abundant waste flow and has the potential to be implemented in supermarkets, small and medium-sized bakeries and industrial bakeries on its returned flows.

Technical and environmental analyses were performed to determine potential tradeoffs of four proposed scenarios to valorise stale bread into a fungal based food product rich in protein. The results from the hotspot analysis indicate that the choice of the medium used in the inoculum production has a large influence on the environmental and technical performance. Inoculum production using molasses or glucose as medium, Sc. II and III respectively, are not preferred from an environmental perspective. Sc. I and Sc. IV, which uses surplus bread and backslopping, showed the lowest environmental impacts in all categories studied here, while maintaining important characteristics such as high protein content. Therefore, it is recommended that such alternatives should be further investigated for the technical feasibility of the process. Moreover, the hotspot analysis indicated that for all scenarios assessed, the fermentation step and drying of bread have a significant impact on the environmental burdens. Therefore, improvements aimed at environmental gains in the fungal biomass production should focus on alternatives for decreasing the fermentation time and consequently the electricity consumption, and on the development of alternative processes in which the drying of bread is not required.

None of the scenarios performed best in all of the parameters analysed. Therefore, it is not possible to draw a simple conclusion regarding the preferred scenario. The decision 
will ultimately be made according to the technical, environmental or economic agenda of the decision-makers. The contribution of this study is to highlight the trade-offs inherently involved in the decision process within the product development and to provide guidance for further development of the process.

Bread waste has the potential to be retained in the food chain by applying a SSF process using the edible fungus $N$. intermedia. The study has integrated environmental considerations into the early stages of the development of a fungal food product, showing which scenario has the best environmental performance and highlighting trade-offs and the parts of the process that are hotspots and should, thereby, be in focus when optimizing the process. This approach is suggested to contribute to a sustainable way to handle otherwise wasted bread, consistent with a circular economy, and it provides a broader base for the developers of the technology to make sustainable decisions during process optimisation.

Author Contributions: Conceptualization, P.B. and R.G.; methodology, P.B., R.G., K.B. and M.J.T.; validation, P.B., R.G., K.B. and M.J.T.; formal analysis, P.B., R.G., K.B. and M.J.T.; investigation, P.B. and R.G.; resources, K.B. and M.J.T.; data curation, P.B. and R.G.; writing-original draft preparation, P.B. and R.G.; writing-review and editing, P.B., R.G., K.B. and M.J.T.; visualization, P.B. and R.G.; supervision, K.B. and M.J.T.; project administration, M.J.T.; funding acquisition, M.J.T. All authors have read and agreed to the published version of the manuscript.

Funding: This research was funded by the Swedish Agency for Economic and Regional Growth (Tillväxtverket) via the European Union European Regional Development Fund within the project "Ways2Taste".

Institutional Review Board Statement: Not applicable.

Informed Consent Statement: Not applicable.

Data Availability Statement: Not applicable.

Conflicts of Interest: The authors declare no conflict of interest.

\section{References}

1. FAO. The State of Food and Agriculture 2019: Moving Forward on Food Loss and Waste Reduction; Food and Agriculture Organization of the United Nations: Rome, Italy, 2019.

2. Hartmann, C.; Siegrist, M. Consumer perception and behaviour regarding sustainable protein consumption: A systematic review. Trends Food Sci. Technol. 2017, 61, 11-25. [CrossRef]

3. Godfray, H.C.J.; Aveyard, P.; Garnett, T.; Hall, J.W.; Key, T.J.; Lorimer, J.; Pierrehumbert, R.T.; Scarborough, P.; Springmann, M.; Jebb, S.A. Meat consumption, health, and the environment. Science 2018, 361, eaam5324. [CrossRef] [PubMed]

4. Filho, P.F.S.; Nair, R.B.; Andersson, D.; Lennartsson, P.R.; Taherzadeh, M.J. Vegan-mycoprotein concentrate from pea-processing industry byproduct using edible filamentous fungi. Fungal Biol. Biotechnol. 2018, 5, 5. [CrossRef]

5. Moore, D.; Chiu, S.W. Fungal products as food. Fungal Divers. Res. Ser. 2001, 6, 223-251.

6. Gmoser, R.; Fristedt, R.; Larsson, K.; Undeland, I.; Taherzadeh, M.J.; Lennartsson, P.R. From stale bread and brewers spent grain to a new food source using edible filamentous fungi. Bioengineered 2020, 11, 582-598. [CrossRef] [PubMed]

7. Shurtleff, W.; Aoyagi, A. The Book of Tempeh; Harper \& Row, Publishers: New York, NY, USA, 1979.

8. Wiebe, M. Myco-protein from Fusarium venenatum: A well-established product for human consumption. Appl. Microbiol. Biotechnol. 2002, 58, 421-427. [CrossRef] [PubMed]

9. Smetana, S.; Mathys, A.; Knoch, A.; Heinz, V. Meat alternatives: Life cycle assessment of most known meat substitutes. Int. J. Life Cycle Assess. 2015, 20, 1254-1267. [CrossRef]

10. Melikoglu, M.; Webb, C. Chapter 4-Use of Waste Bread to Produce Fermentation Products. In Food Industry Wastes; Kosseva, M.R., Webb, C., Eds.; Academic Press: San Diego, CA, USA, 2013; pp. 63-76.

11. WRAP, H. Link Consumer Strategies, Campden BRI. In Reducing Household Bakery Waste; WRAP, Waste and Resource Action Programme: Banbury, UK, 2011.

12. Brancoli, P.; Rousta, K.; Bolton, K. Life cycle assessment of supermarket food waste. Resour. Conserv. Recycl. 2017, 118, 39-46. [CrossRef]

13. Brancoli, P.; Lundin, M.; Bolton, K.; Eriksson, M. Bread loss rates at the supplier-retailer interface-Analysis of risk factors to support waste prevention measures. Resour. Conserv. Recycl. 2019, 147, 128-136. [CrossRef]

14. Ghosh, R.; Eriksson, M. Food waste due to retail power in supply chains: Evidence from Sweden. Glob. Food Sec. 2019, 20, 1-8. [CrossRef] 
15. Eriksson, M.; Ghosh, R.; Mattsson, L.; Ismatov, A. Take-back agreements in the perspective of food waste generation at the supplier-retailer interface. Resour. Conserv. Recycl. 2017, 122, 83-93. [CrossRef]

16. Papargyropoulou, E.; Lozano, R.; Steinberger, J.K.; Wright, N.; bin Ujang, Z. The food waste hierarchy as a framework for the management of food surplus and food waste. J. Clean. Prod. 2014, 76, 106-115. [CrossRef]

17. Brancoli, P.; Bolton, K.; Eriksson, M. Environmental impacts of waste management and valorisation pathways for surplus bread in Sweden. Waste Manag. 2020, 117, 136-145. [CrossRef]

18. Cucurachi, S.; van der Giesen, C.; Guinée, J. Ex-ante LCA of Emerging Technologies. Procedia CIRP 2018, 69, 463-468. [CrossRef]

19. Jeswiet, J.; Hauschild, M. EcoDesign and future environmental impacts. Mater. Des. 2005, 26, 629-634. [CrossRef]

20. McAloone, T.C.; Bey, N. Environmental Improvement through Product Development: A Guide; Danish Environmental Protection Agency: Copenhagen, Denmark, 2009.

21. European Commission. Innovating for Sustainable Growth: A Bioeconomy for Europe; Publications Office of the European Union: Brussels, Belgium, 2012.

22. Eriksson, M.; Strid, I.; Hansson, P.A. Carbon footprint of food waste management options in the waste hierarchy-A Swedish case study. J. Clean. Prod. 2015, 93, 115-125. [CrossRef]

23. Vandermeersch, T.; Alvarenga, R.A.F.; Ragaert, P.; Dewulf, J. Environmental sustainability assessment of food waste valorization options. Resour. Conserv. Recycl. 2014, 87, 57-64. [CrossRef]

24. Lam, C.-M.; Yu, I.K.M.; Hsu, S.-C.; Tsang, D.C.W. Life-cycle assessment on food waste valorisation to value-added products. J. Clean. Prod. 2018, 199, 840-848. [CrossRef]

25. Gmoser, R.; Sintca, C.; Taherzadeh, M.J.; Lennartsson, P.R. Combining submerged and solid state fermentation to convert waste bread into protein and pigment using the edible filamentous fungus N. intermedia. Waste Manag. 2019, 97, 63-70. [CrossRef]

26. Melikoglu, M.; Lin, C.S.K.; Webb, C. Solid state fermentation of waste bread pieces by Aspergillus awamori: Analysing the effects of airflow rate on enzyme production in packed bed bioreactors. Food Bioprod. Process. 2015, 95, 63-75. [CrossRef]

27. Buyle, M.; Audenaert, A.; Billen, P.; Boonen, K.; Van Passel, S. The future of ex-ante LCA? Lessons learned and practical recommendations. Sustainability 2019, 11, 5456. [CrossRef]

28. Wiloso, E.I.; Sinke, P.; Setiawan, A.A.R.; Sari, A.A.; Waluyo, J.; Putri, A.M.H.; Guinée, J. Hotspot identification in the Indonesian tempeh supply chain using life cycle assessment. Int. J. Life Cycle Assess. 2019, 24, 1948-1961. [CrossRef]

29. Dunn, J.B.; Mueller, S.; Wang, M.; Han, J. Energy consumption and greenhouse gas emissions from enzyme and yeast manufacture for corn and cellulosic ethanol production. Biotechnol. Lett. 2012, 34, 2259-2263. [CrossRef]

30. Jungbluth, N.; Nowack, K.; Eggenberger, S.; König, A.; Keller, R. Untersuchungen zur umweltfreundlichen EiweissversorgungPilotstudie; ESU-services GmbH für das Bundesamt für Umwelt (BAFU): Bern, Switzerland, 2016.

31. Wang, R.; Gmoser, R.; Taherzadeh, M.J.; Lennartsson, P.R. Solid-state fermentation of stale bread by an edible fungus in a semi-continuous plug-flow bioreactor. Biochem. Eng. J. 2021, 169, 107959. [CrossRef]

32. Huijbregts, M.A.J.; Steinmann, Z.J.N.; Elshout, P.M.F.; Stam, G.; Verones, F.; Vieira, M.D.M.; Hollander, A.; Zijp, M.; Van Zelm, R. ReCiPe 2016: A harmonized life cycle impact assessment method at midpoint and endpoint level Report I: Characterization. Int. J. Life Cycle Assess. 2017, 22, 138-147. [CrossRef]

33. Gmoser, R.; Lennartsson, P.R.; Taherzadeh, M.J. From surplus bread to burger using filamentous fungi at bakeries: Technoeconomical evaluation. Clean. Environ. Syst. 2021, 2, 100020. [CrossRef]

34. Ingledew, W.M.; Austin, G.D.; Kraus, J.K. Commercial yeast production for the fuel ethanol and distilled beverage industries. In The Alcohol Textbook, 5th ed.; Nottingham University Press: Nottingham, UK, 2009; pp. 127-144.

35. Piccinno, F.; Hischier, R.; Seeger, S.; Som, C. From laboratory to industrial scale: A scale-up framework for chemical processes in life cycle assessment studies. J. Clean. Prod. 2016, 135, 1085-1097. [CrossRef]

36. Ward, O.P. Production of recombinant proteins by filamentous fungi. Biotechnol. Adv. 2012, 30, 1119-1139. [CrossRef]

37. Nair, R.B. Integration of first and second generation bioethanol processes. In Swedish Centre for Resource Recovery; University of Borås: Borås, Sweden, 2017.

38. Ferreira, J.A.; Lennartsson, P.R.; Edebo, L.; Taherzadeh, M.J. Zygomycetes-based biorefinery: Present status and future prospects. Bioresour. Technol. 2013, 135, 523-532. [CrossRef] [PubMed] 